\title{
DETERMINATION OF THE NUMBER OF NURSES FOR HOSPITAL AID IN THE REPUBLIC OF BULGARIA
}

\author{
Greta Koleva $^{1}$, Despina Georgieva ${ }^{2}$, IrinkaHristova ${ }^{3}$
}

\begin{abstract}
:
Introduction: The nurses in the Republic of Bulgaria addressed a number of official demands to the Ministry of Health, one of them was to work out a long-term strategy for the development of standards, including detailed minimal requirements for the number of staff for both hospital, and outpatient care.

Objectives: The goal of the current report is a summary of the regulatory documents, concerning the number of nurses in the Republic of Bulgaria, in context of the global practices.

Methods: Current medical standards in the Republic of Bulgaria are being taken into account, and methods for determining the number of nurses in other countries.

Results: In the period between November and December 2020, within the public consultations for projects of different Regulations for approval of medical standards, the proposed and developed methods by the Bulgarian association of health professionals in nursing to be included in the standards, which concern calculating the necessary staff of nurses, was not admitted for inclusion in any of those standards.

Conclusions: Until now, the number of active nurses in the Republic of Bulgaria in all active medical standards is calculated either on the basis of doctors (not patients), or it's pointed out that the methods of calculating the sufficient number of nurses may be applied. It should be noted that the International Council of Nurses, actually does not recommend universal methods for all countries worldwide.
\end{abstract}

UDC Classification: 331.1, DOI: https://doi.org/10.12955/pmp.v2.174

Keywords: Nurse Staffing Norms; Workforce Planning; Nurse; Employment; Nurse-to-patient ratio;

\section{Introduction}

Bulgaria's health profile for 2019 shows some progress in the solution of problems concerning manpower in health care - The National Health card may be used as a means of planning and distribution of that manpower. But it's not an instrument for providing quality of the services offered there. The nurses in the Republic of Bulgaria addressed a number of official demands to the Ministry of Health, one of them was to work out a long-term strategy for the development of standards, including detailed minimal requirements for the number of staff for both hospital, and outpatient care (OECD, 2019).

The positive effect of available medical standards relates to using them as an instrument for both improvement and a guarantee of the quality of the provided care, and the assessment of the changes' results, which are directly related to the patients. Also, the advantages for healthcare professionals are apparent, because of a reduction of frustration, of both organizational and medical errors, improvement in the communication between them professionals, and providing effective medical protection by avoiding risk.

\section{Objectives}

The goal of the current report is a summary of the regulatory documents, concerning the number of nurses in the Republic of Bulgaria, in context of the global practices.

\section{Methods}

Current medical standards in the Republic of Bulgaria are being taken into account, and methods for determining the number of nurses in other countries.

\section{Results}

In 2020, the Bulgarian association of health professionals in nursing (BAHPN) published methods forcalculating the necessary staff of nurses that are applicable for developing standards, being developed for current planning, and for identifying either shortages or surplus of healthcare

\footnotetext{
${ }^{1}$ Ruse University „Angel Kanchev“, Ruse, Bulgaria; Department of Health care, Faculty of Public health and Health care, gkoleva@ uni-ruse.bg ORCID: https://orcid.org/0000-0002-1270-5396

${ }^{2}$ Ruse University „Angel Kanchev“, Ruse, Bulgaria; Department of Health care, Faculty of Public health and Health care, dpgeorgieva@uni-ruse.bg ORCID: https://orcid.org/0000-0001-7622-3145

${ }^{3}$ Ruse University „Angel Kanchev“, Ruse, Bulgaria; Department of Health care, Facultyof Public health and Health care,ihristova@uni-ruse.bgORCID: https://orcid.org/0000-0002-4859-2602
} 
professionals in hospitals. According to the proposed methods, two types of care are defined - direct and indirect, and a classification offered by the International Council of Nurses (ICN), is used. The basic criteria, admitted for the determination of necessities of nurses are: the number of patients, the time needed for providing direct and indirect care, and the degree of the patient's severe condition. The methods are easy to apply and to calculate, thus sufficient number of nurses guarantees both quality and equality, as well as the succession of health care throughout the day (BAHPN, 2020).

In the period between November and December 2020, within the public consultations for projects of different Regulations for approval of medical standards - Neurosurgery, Pediatric surgery, and Vascular surgery. The methodology developed and proposed by BAHPN for calculating the required staff (nurses) to be included in the standards has not been accepted. (Ministry of Health Republic of Bulgaria, 2020a; Ministry of Health Republic of Bulgaria, 2020b; Ministry of Health Republic of Bulgaria, 2020c).

\section{Recommended ratios nurse-patient}

According to all European and American recommendations, and the White Book of levels of nurse staff for the safety of both manpower and the patients, a proper ratio needs to be aimed at forming the teams concerning the nurses' additional qualification.

Globally, the advisable ratios for the different countries depend on the context and specific conditions, and therefore the ICN neither recommends, nor supports ratios (SPSC \& ICN White Paper, 2019).

Both the ICN Safety Patient Centre and Saudi Patient Safety Center (SPSC) in Saudi Arabia, have published in 2019 a White Book of the nursing staff levels for both the safety of patients, and the safety of manpower which unites proofs from a wide range of sources that embrace various countries and contexts, showing that the proper number of nurses in the right time and place, provides quality and safety of the population, which they serve, and that'll help keep nurses. The represented ratios are developed in the context of the model of providing health care in Saudi Arabia, and they are based on studies, based on proofs for the safe provision of care (Aiken et al., 2010).

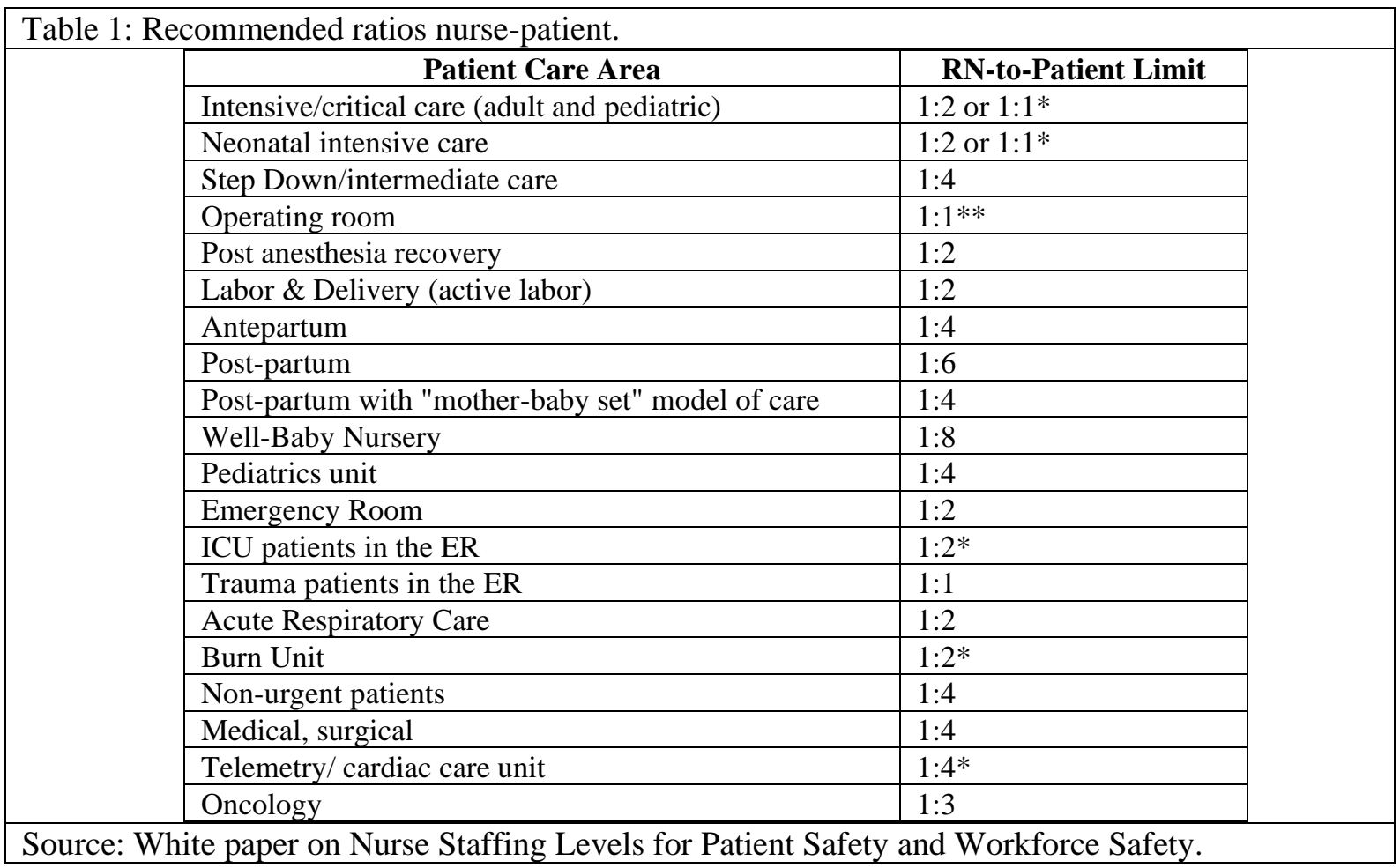

According to Application 1 from the Law of the number of the nursing staff in Scotland, a Triangular model of determining the needs in staff level, is used:

1. Patients' acuteness - elderly patients lead to higher levels of acuteness - fallings and decubitus (quality indicators). This requires a larger number of nurses $-1: 1$;

2. Professional estimation - the nurses' competence of making informed decisions; 
3. Quality indicators - those indicators that are highly sensitive to the care provided only by nurse, are being estimated. Such as - patients falling from the bed, decubitus acquired in hospital, medicament errors - during preparation, administration, and oversight of medication intake by a nurse. The number of quality indicators are taken separately and analyzed whether the level of nursing staff is met, then whether this level has contributed to this event (Nurse staffing levels (Wales) Act, 2016).

Many registered nurses raise the issue that a low level of staff threatens the quality of care of the patients in the hospitals for emergency medical aid. In response to those fears, in 1999 California became the first state in the United States, where a law was passed for a minimal ratio between nurses and patients in hospitals where emergency medical aid is being conducted.

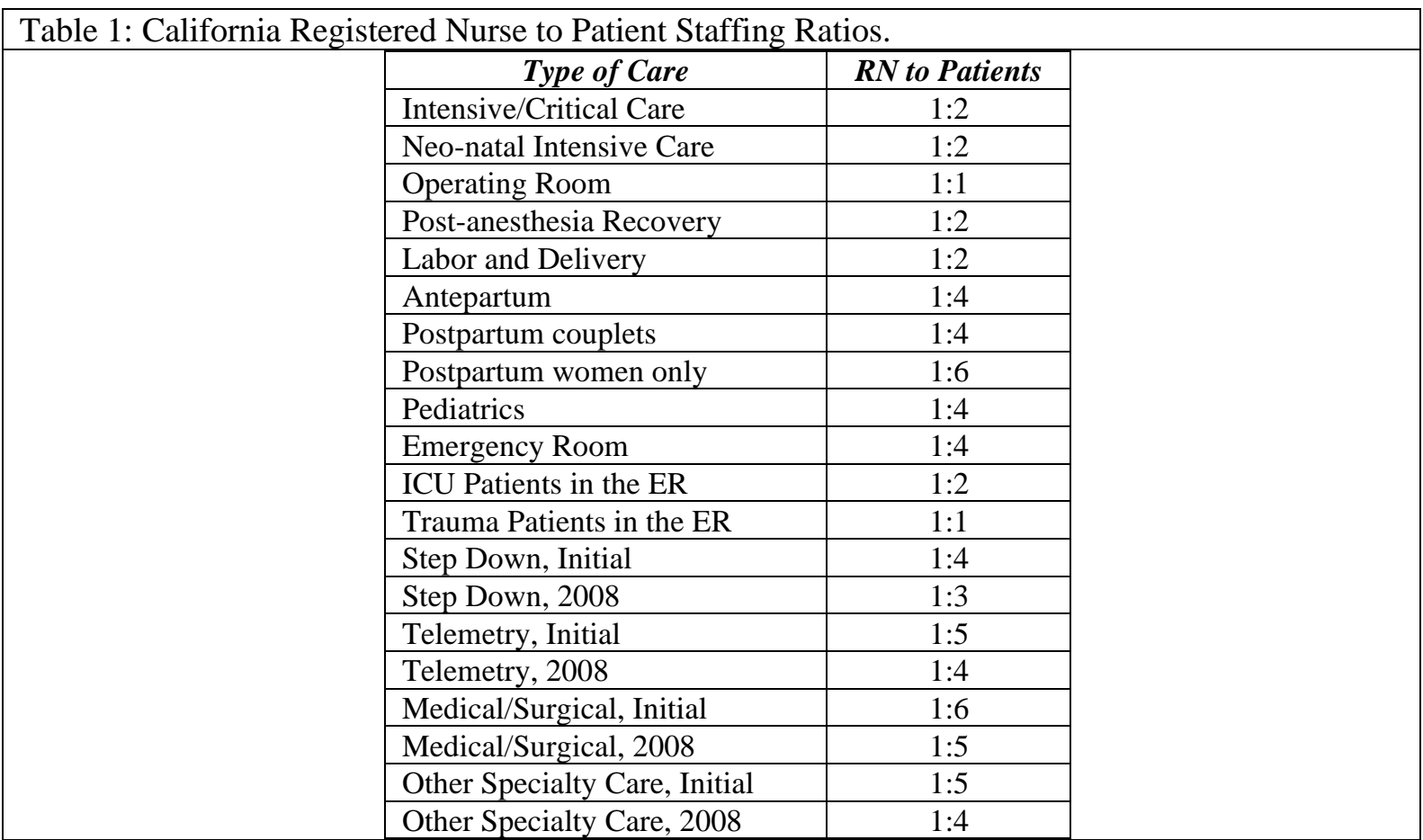

Source: California RN Staffing Ratio Law. (2004)

The law defines specific number ratios between nurses and patients for acute care, acute psychiatric and specialized hospitals in California. The ratios are the maximum number of patients who can be assigned to a registered nurse during one shift. The law demands additional registered nurses to be defined via a documented system for the classification of patients that measures the needs of both the patients and medical care, including the disease severity and the clinical need complexity. The law also confines the nominations of unlicensed nursing staff in hospital clinical zones, where they haven't shown any competence, training or orientation.

\section{Discussion}

Based on BAHPN's proposed methods, it's evident that for a ward with a capacity of 40 beds, with 80\% (32 patients) occupied, 17 nurses are needed. The methods propose hospital attendants to be employed in 4 of those jobs.

Practically, a monthly schedule with 13 nurses in a month of 22 workdays and 8-hour working time, on day and night duties, without reducing hours for night shift. 176 hours need to be worked out, that is 14 shifts for a single nurse. For example: if 4 nurses are envisaged for day shift, and 3 for night shift, their total number is 15 or 16 for the respective month. In order to not spend any extra hours, the balance of the teams would be disturbed.

If the number of nurses is reduced, it'll turn out that 3 nurses on day shift are needed for 10 patients. If the number of nurses for night shift is reduced, then 2 nurses are needed for 32 patients, respectively one nurse for 16 patients. This calculation is in case no one is absent due to illness or paid annual leave.

As a matter of fact, the proposed methods verifies the rule the Bulgarian nurses are fighting against, about determining the necessity of nurses for hospital aid as precisely 1:2 - one doctor: 2 nurses. 
Also, in BAHPN's proposed methods it is pointed out that when there's shortage of nurses, $30 \%$ of the needed human resource of health care professionals is allowed to be occupied by health assistants/ hospital attendants with a diploma for graduated professional training, who can perform basic health care, and to assist health care specialists' work in hospitals (BAHPN, 2020). Why is it necessary to reduce the number of nurses, in order to be provided for the occupation of a health assistant/ hospital attendant? New jobs can be created for different professions to support the nurse's work. Health Assistants and Caregivers "... may only work in the structures of post-treatment, social and community facilities". Only health assistants in the relevant position can be employed in the hospitals for active treatment, and no hospital attendants (Ordinance №72, 2012; Ordinance №73, 2012).

\section{Conclusions}

The tendency of reducing the number of nurses is preserved during the last years. At the same time, due to expensive hospital treatment, the average hospital stays of patients are reduced, leading to a greater number of hospitalized patients. Along with this, the acuteness of diseases subject to hospitalization, also increases and respectively, the need of more intensive care. The number of health care specialists at both a European scale and globally, is defined according to the kind, complexity, specificity and intensity of the provided care and acuteness of the patients' disease, thus forming the capacity of the health care required. The necessity of applying the methods of calculating the needs of nursing staff is recommended by the ICN.

Until now, the number of active nurses in the Republic of Bulgaria in all active medical standards, is calculated either on the basis of doctors (not patients), or it is pointed out that the methods of calculating the sufficient number of nurses may be applied. It should be noted that the International Council of Nurses, actually does not recommend universal methods for all countries worldwide.

\section{References}

Aiken, L. H., Sloane, D. M., Cimiotti, J. P., Clarke, S. P., Flynn, L., Seago, J. A., Spetz, J., \& Smith, H. L. (2010). Implications of the California nurse staffing mandate for other states. Health services research, 45(4), 904-921. https://doi.org/10.1111/j.1475-6773.2010.01114.x

BAHPN/Bulgarian association of health professionals in nursing. (2020). Methodology for calculating the required staff (nurses), applicable in the development of standards. Retrieved from https://nursingbg.com/docs/nb/pnds/0_Metodika_Personal.pdf

California RN Staffing Ratio Law. (2004). 2004-R-0212. Retrieved from https://www.cga.ct.gov/2004/rpt/2004-r-0212.htm

Ministry of Health Republic of Bulgaria. (2020a). REFERENCE for reflecting the opinions received within the framework of the public consultations on the draft Ordinance for approval of the medical standard "Pediatric Surgery". Retrieved from https://www.mh.government.bg/media/filer_public/2020/12/31/2_spravka_detska_hirurgiya_za_podpis.pdf

Ministry of Health Republic of Bulgaria. (2020b). REFERENCE for reflecting the opinions received within the framework of the public consultations on the draft Ordinance for approval of the medical standard "Neurosurgery". Retrieved from https://www.mh.government.bg/media/filer_public/2020/12/31/2_spravka_nevrohirurgiya_za_podpis.pdf

Ministry of Health Republic of Bulgaria. (2020c). REFERENCE for reflecting the opinions received within the framework of the public consultations on the draft Ordinance for approval of the medical standard "Vascular Surgery ". Retrieved from https://www.mh.government.bg/media/filer_public/2020/12/31/2_spravka_sadova_hirurgiya_za_podpis.pdf

Nurse staffing levels (Wales) Act. (2016). 8.a Appendix 1. Retrieved from https://sbuhb.nhs.wales/about-us/key-documentsfolder/quality-and-safety-committee-papers/quality-and-safety-committee-august-2018/8a-appendix-1-nurse-staffing-walesreport-docx-pdf/

OECD/European Observatory on Health Systems and Policies. (2019). Bulgaria: Country Health Profile 2019, State of Health in the EU, OECD Publishing, Paris/European Observatory on Health Systems and Policies, Brussels.

Ordinance № 72 of September 26, (2012).On acquiring a qualification in the profession "Health Assistant". Retrieved from https://www.navet.government.bg/bg/media/723010-naredba-doi-zdraven-asistent.pdf

Ordinance № 73 of September 26, (2012).On acquiring a qualification in the profession "Caregiver". Retrieved from https://www.navet.government.bg/bg/media/723020-naredba-doi-bolnogledach.pdf

Saudi Patient Safety Center; International Council of Nurses. Nurse Staffing Levels For Patient Safety And Workforce Safety. SPSC and ICN White Paper. Riyadh, Saudi Arabia; (2019). (Available at spsc.gov.sa and icn.ch) 